\title{
Review
}

\section{Glycobiology of cell death: when glycans and lectins govern cell fate}

\author{
RG Lichtenstein ${ }^{\star, 1}$ and GA Rabinovich ${ }^{\star, 2,3}$
}

\begin{abstract}
Although one typically thinks of carbohydrates as associated with cell growth and viability, glycosylation also has an integral role in many processes leading to cell death. Glycans, either alone or complexed with glycan-binding proteins, can deliver intracellular signals or control extracellular processes that promote initiation, execution and resolution of cell death programs. Herein, we review the role of glycans and glycan-binding proteins as essential components of the cell death machinery during physiologic and pathologic settings.
\end{abstract}

Cell Death and Differentiation (2013) 20, 976-986; doi:10.1038/cdd.2013.50; published online 24 May 2013

\section{Bullet Points}

(1) Glycosylation of classical death receptors fine-tunes cell death programs.

(2) Intracellular lectins and glycan-modifying enzymes mediate autophagy and control host immunity and inflammation.

(3) Endogenous lectins and glycans are critical signals in the resolution of cell death.

\section{Open Questions}

(1) Is there a hallmark 'glycosylation signature' that characterizes the initiation, execution and resolution of cell death programs in physiologic and pathologic settings?

(2) How do C-type lectins tailor adaptive immunity following phagocytosis of apoptotic cells?

(3) What is the precise role of intracellular and extracellular galectins in the control of cell death programs?

\section{Historical Overview \\ During the 1960s as part of the revolution in developmental biology, Lockshin and Williams ${ }^{1}$ coined the term 'programmed cell death (PCD)'. Several years later, Kerr and co-workers ${ }^{2}$ defined the morphological changes in cells undergoing this process, also known as apoptosis. At that time, glycobiology, which is the study of carbohydrates and their recognition by motif-specific carbohydrate-binding proteins or lectins, lagged}

far behind the studies that defined the structural and cellular biology of cell death. Although lectins were already known because of their ability to agglutinate red blood cells, ${ }^{3}$ the involvement of lectins and glycans in PCD had not been elucidated. Two decades later, pioneering studies suggested that lectin-like molecules constitutively expressed on the surface of macrophages can selectively recognize changes on glycans decorating the surface of apoptotic thymocytes, ${ }^{4,5}$ although these studies likewise did not provide substantial insight into the mechanisms by which lectin-glycan interactions regulate cell death. More compelling evidence was obtained several years later, when Griffiths and co-workers ${ }^{6}$ identified apoptotic changes within lymphoid tissues after injection of plant lectins in vivo, followed by additional studies $^{7,8}$ documenting cell shrinkage and DNA fragmentation in lymphocytes exposed in vitro to plant lectins. This approach set the basis for therapeutic strategies aimed at eliminating aberrantly glycosylated cancer cells. ${ }^{9}$

The emergence of functional studies on animal lectins during the 1990s has provided the appropriate framework to better understand their roles in cell death. ${ }^{10}$ Galectins can function inside the cells by modulating signaling pathways, ${ }^{11}$ although they also act extracellularly by establishing multivalent interactions with cell surface glycans and delivering signals that lead to disruption of cellular homeostasis. ${ }^{12-14}$

We discuss here the contribution of glycan-lectin interactions to the initiation, execution and resolution of apoptosis and their emerging roles in other cell death programs including autophagy. Understanding the function of lectin-glycan recognition systems in cell death will facilitate

\footnotetext{
${ }^{1}$ Avram and Stella Goren-Goldstein, Department of Biotechnology Engineering, Faculty of Engineering, Ben-Gurion University of the Negev, Beer-Sheva 84105, Israel; ${ }^{2}$ Laboratorio de Inmunopatología, Instituto de Biología y Medicina Experimental (IBYME), Consejo Nacional de Investigaciones Científicas y Técnicas (CONICET), Ciudad de Buenos Aires, Buenos Aires C1428A, Argentina and ${ }^{3}$ Laboratorio de Glicómica Funcional, Departamento de Química Biológica, Facultad de Ciencias Exactas y Naturales, Universidad de Buenos Aires, Buenos Aires C1428A, Argentina

${ }^{*}$ Corresponding author: RG Lichtenstein, Avram and Stella Goren-Goldstein, Department of Biotechnology Engineering, Faculty of Engineering, Ben-Gurion University of the Negev, Beer-Sheva 84105, Israel. Tel: +972 8 6479084; Fax: +972 8 6472983; E-mail: ruha@ @gu.ac.il

or GA Rabinovich, Laboratorio de Inmunopatología, Instituto de Biología y Medicina Experimental (IBYME), Consejo Nacional de Investigaciones Científicas y Técnicas (CONICET), Ciudad de Buenos Aires, Buenos Aires C1428A, Argentina. Tel: +54 1147832869 (ext 266); Fax: +54 114786 2564; E-mail: gabyrabi@gmail.com Keywords: glycans; lectins; galectins; apoptosis; autophagy

Abbreviations: GaINAc, N-acetyl galactosamine; JNK, c-Jun N-terminal kinase; Bcl-2, B-cell lymphoma-2; NF- $\kappa$ B, nuclear factor-kappa-light chain enhancer of B cells; TIM, T-cell immunoglobulin mucin; Smac, second mitochondria-activator of caspases

Received 27.2.13; revised 08.4.13; accepted 16.4.13; Edited by M Piacentini; published online 24.5.13
} 
the implementation of novel therapeutic strategies aimed at controlling unbalanced cell proliferation and survival in several pathologic conditions.

\section{Lectins and Glycans in the Initiation of Cell Death}

The surface of the living cells is decorated by a complex layer of glycosylated molecules that store relevant biological information. The glycosylation machinery is responsible for assembling a diverse repertoire of glycan structures, collectively termed 'glycome', through the synchronized action of a portfolio of glycan-modifying enzymes including glycosyltransferases and glycosidases. To create the large repertoire of glycan structures, each of these glycosyltransferases uses a single-nucleotide sugar substrate and forms specific linkages between one monosaccharide and a glycan precursor. The nature and extent of glycosylation of a given protein depends on the presence of $N$ - and $O$-linked
Tumor cell glycosylation sites in the protein backbone, as well as on the expression and activities of particular glycosyltransferases and glycosidases within a specific cell or tissue. ${ }^{15}$ Membraneanchored or soluble lectins are responsible of decoding glycan-containing information and controlling cellular homeostasis by modulating signaling, receptor trafficking and endocytosis. ${ }^{16,17}$ Through different mechanisms, lectin-glycan recognition systems have important roles in the initiation of cell death (Figure 1).

\section{Glycans Exposed on Death Receptors Control Cell Death}

Glycosylation can modulate the function of death receptors including CD95 (Fas) and tumor necrosis factor receptor 1 (TNFR1) by allowing or sterically hindering their ligation by FasL or TNF superfamily ligands. Several glycosyltransferases and glycosidases comprising the 'glycosylation machinery' control death by displaying or

Immune cell

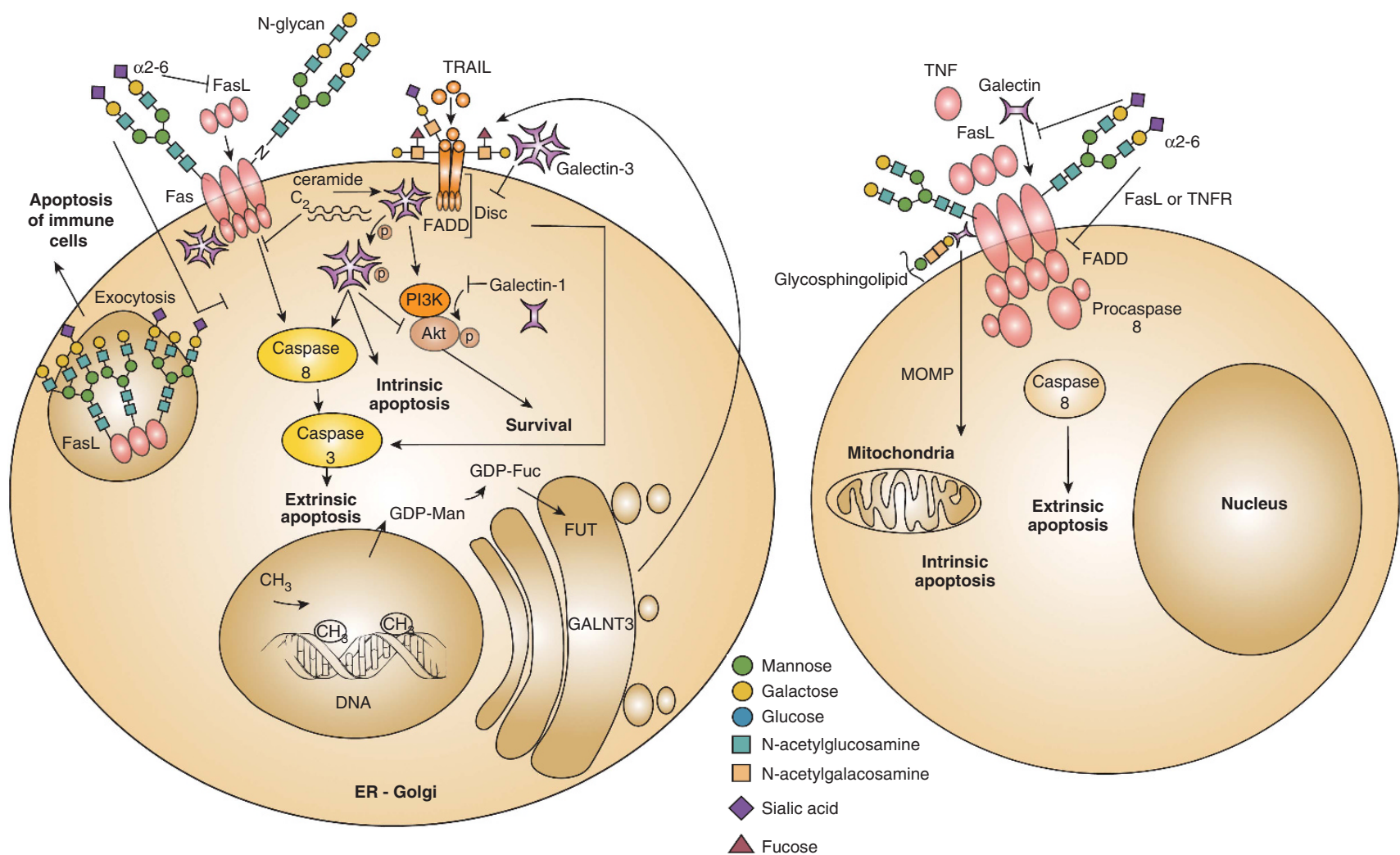

Figure 1 Influence of glycans and glycan-binding proteins in death receptor signaling and function. In tumor cells, alterations of the components comprising the 'glycosylation machinery' generate aberrant O-glycans and N-glycans on Fas and TRAIL receptors, which modulate apoptosis. Upregulation of GALNT3, FUT and GDP-FUC as a result of DNA methylation increases tumor cell sensitivity to extrinsic apoptosis through TRAIL. In addition, $\alpha 2-6$-linked sialic acid decorating Fas receptor on tumor cells blocks Fas ligand internalization, Fas-FADD complex formation and activation of caspase-8 and -3 , thus attenuating cell death via the extrinsic pathway. Intracellular and extracellular galectins can modulate survival and apoptotic signaling pathways in tumor cells. Intracellular galectin-1 decreases Akt activity and induces apoptosis. By contrast, intracellular galectin-3 either free or associated with C2-ceramide cooperates with PI3K/Akt to increase tumor cell survival. However, in some cases, intracellular galectin-3 promotes extrinsic and intrinsic apoptosis, either through association with Fas or via phosphorylation at serine 6 . Extracellular galectin-3 inhibits the extrinsic apoptosis cascade by anchoring TRAIL receptors through glycosylation-dependent mechanisms. Moreover, glycosylation of intracellular Fas ligands in tumor cells facilitates ligand secretion as a strategy of tumor-immune escape (a). Fas receptor on immune cell bears $\mathrm{N}$-glycans to stabilize complexes like DISC, generated during the execution of the extrinsic apoptotic pathway. Increased $\alpha 2-6$ sialylation of $N$-glycans impairs Fas internalization, FADD-Fas complex formation, activation of caspase-8 and -3 and T-cell homeostasis. $\alpha 2-6$ sialylation further interferes with galectin-1 binding to glycoproteins (e.g. CD45, CD43), and also interrupts ligand binding to TNFR1 on macrophages and decreases apoptosis. Galectin-1 interacts with Fas on resting T cells and stimulates both the intrinsic and extrinsic apoptotic signaling routes (b). GALNT3, N-acetyl galactosyltransferase-3; FUT, fucosyltransferase; GDP-FUC, guanosine diphosphate-fucose; Akt, serine/threonine-specific protein kinase; Ser6, serine at position 6; CD45, protein tyrosine phosphatase; CD43; sialophorin 
masking cell surface glycans. Upregulation of particular glycosyltransferases

( $N$-acetyl galactosamine (GalNAc) transferases and fucosyltransferase) leads to fucosylated core-2 O-glycans in TNF-related apoptosis-inducing ligand receptor (TRAIL-R1/ DR4 and TRAIL-R2/DR5), which increases the sensitivity of cancer cells to TRAIL-induced apoptosis. Exposure to glycosylated TRAIL enhances recruitment of death-inducing signaling complex (DISC), Fas-associated death domain (FADD) and caspase-8, all of which are involved in the extrinsic apoptotic pathway, providing a potential predicative marker for TRAIL-based cancer therapy. ${ }^{18}$ Consistent with these observations, a lower degree of fucosylation, which occurs by mutation of the GDP-mannose-4-6-dehydratase (GMDS) gene increases resistance to TRAIL-induced apoptosis in human colon cancer cells. ${ }^{19}$ The GMDS is an essential enzyme responsible for converting GDP-mannose into GDPfucose in the de novo fucosylation pathway. As a result, tumor cells evade NK cell-dependent immune surveillance. ${ }^{19}$ This observation was further supported by removing the DNA's methyl groups of highly resistant tumor cells. ${ }^{20}$ Treatment with the methyltransferase inhibitor zebularine decreases DNA methylation and increases the expression of fucosylationrelated genes, which subsequently decrease resistance to TRAIL-induced apoptosis ${ }^{20}$ (Figure 1a).

$\mathrm{N}$-glycosylation of death receptors also regulates apoptotic programs. Whereas TRAIL bears two potential $O$-glycosylation sites, ${ }^{18}$ Fas contains two $\mathrm{N}$-glycosylation sites. ${ }^{21}$ In the presence of Fas ligand, Fas-associated $\mathrm{N}$-glycans contribute to stabilize the core DISC structure, DISC-DISC interactions and procaspase-8 oligomerization ${ }^{21}$ (Figure 1b). By contrast, when Fas is aberrantly glycosylated because of localization of the protein tyrosine phosphatase SHP-1 in the endoplasmic reticulum (ER), Fas fails to oligomerize in response to Fas ligand and T-cell homeostasis is impaired. ${ }^{22}$ Accordingly, sialic acid residues decorating $\mathrm{N}$-glycans reduce the sensitivity of B-cell lymphomas to Fas ligand-induced apoptosis. ${ }^{23-25}$ More recent studies revealed that $\alpha 2-6$ sialylation blocks Fas internalization, formation of the FasFADD complex and activation of caspase- 8 and -3 in colon carcinoma cells. ${ }^{26}$ However, it remains unclear whether sialic acid residues interfere with Fas signaling or whether the intact glycan structures control particular molecular cascades leading to cell death. In this regard, Schneider and coworkers ${ }^{27}$ found that Fas ligand bears three $\mathrm{N}$-glycans that are essential for its efficient secretion. This effect was substantiated in tumor models showing that heavily glycosylated Fas ligand was associated with exosomes when secreted from malignant cells, possibly to induce apoptosis of Fas-bearing immune cells as a strategy of immune escape. $^{28}$ Thus, glycosylation of death receptors and their canonical ligands may critically regulate the initiation of apoptosis by hindering ligand-receptor interactions, influencing the formation of signaling complexes and/or modulating ligand secretion from effector cells. Solid and hematopoietic malignancies often use their unique glycosylation machinery to modify death receptor's glycans, thereby increasing resistance to apoptosis. However, glycan-binding proteins and glycans may themselves control initiation or termination of lethal signaling. ${ }^{12}$

\section{Cross-talk Between Lectins and Death Receptors in the Initiation of Cell Death}

When endogenous (cell membrane) or exogenous (soluble) glycan-binding proteins are recruited to signaling death receptors (Table 1), the apoptotic machinery is positively or negatively regulated through the establishment of multivalent interactions between glycosylated receptors and glycanbinding proteins. These interactions control signaling thresholds, receptor clustering and endocytosis. ${ }^{12}$ Depending on the activation or differentiation status of $T$ cells, exposure to galectin-1 leads to growth arrest or inhibition of cytokine secretion. ${ }^{29}$ Binding of galectin-1 to $\mathrm{N}$ - and $\mathrm{O}$-glycans on cell

Table 1 Involvement of galectins at different stages of programmed cell death

\begin{tabular}{|c|c|c|c|c|}
\hline Member & Function & Receptor/target protein & Cell type & Reference \\
\hline \multirow[t]{3}{*}{ Galectin-1 } & \multirow[t]{3}{*}{ Proapoptotic } & Fas & T cells & 16,30 \\
\hline & & Akt & Breast carcinoma & 35 \\
\hline & & CD43, CD45 & $\begin{array}{l}\mathrm{T} \text { cells } \\
\text {. }\end{array}$ & $39,46,47$ \\
\hline \multirow[t]{6}{*}{ Galectin-3 } & Proapoptotic & Fas & $B$ and $T$ cell lines & 32 \\
\hline & Antiapoptotic & $\mathrm{C}_{2}$-ceramide & $B$ and $T$ cell lines & 32 \\
\hline & Antiapoptotic & PI3K/Akt & Bladder carcinoma & 33 \\
\hline & Antiapoptotic & TRAIL & Breast carcinoma & 34 \\
\hline & Proapoptotic & Akt & Breast carcinoma & 35 \\
\hline & Antiapoptotic & TRAILR1, TRAILR2 & Colon cancer & 36 \\
\hline Ser6-phosphorylated galectin-3 & Proapoptotic & TRAIL & Breast cancer & 37,38 \\
\hline Galectin-3 & Antiapoptotic & $\mathrm{Bcl}-2$ & $\mathrm{~T}$ cells & 72 \\
\hline Tyr79-, Tyr118-phosphorylated galectin-3 & Antiapoptotic & c-Abl, Arg tyrosine kinase & Carcinoma & 74 \\
\hline Galectin-7 & Proapoptotic & Bcl-2 & Carcinoma & 71 \\
\hline Galectin-8 & Autophaqy & Autophagic proteins & Salmonella-infected cells & 81 \\
\hline Galectin-9 & Proapoptotic & TIM-3 & Th1 cells & 60 \\
\hline \multirow[t]{2}{*}{ Galectin-1 } & \multirow[t]{2}{*}{ Phagocytosis } & Phosphatidylserine recruitment & Activated neutrophils & 102,103 \\
\hline & & CD45 and fodrin & T cells & 111 \\
\hline Galectin-2 & Phaqocytosis & Phosphatidylserine exposure & Activated T cells & 104 \\
\hline \multirow[t]{3}{*}{ Galectin-3 } & \multirow[t]{3}{*}{ Phagocytosis } & Monocytes/macrophages & Apoptotic thymocytes & 93-95 \\
\hline & & MerTK & Apoptotic neutrophils & 101 \\
\hline & & Phosphatidylserine exposure & Activated neutrophils & 102,103 \\
\hline Galectin-4 & Phagocytosis & Phosphatidylserine exposure & Activated T cells & 104 \\
\hline Galectin-8 & Phagocytosis & Phosphatidylserine exposure & HL-60 myeloid cells & 104 \\
\hline
\end{tabular}


surface glycoproteins triggers apoptosis of activated T cells. ${ }^{16}$ However, galectin-1 also binds to resting $T$ cells and contributes to the amplification of Fas ligand-mediated apoptosis. $^{30}$ This effect involves direct interaction of galectin-1 with Fas, upregulation of Fas on the surface of resting $T$ cells and changes in the mitochondrial membrane potential $^{30}$ (Figure 1b). In addition, sialylation-dependent regulation of apoptosis has been demonstrated for TNFR1, an alternative death receptor in macrophages. Lack of $\alpha 2-6$-linked sialic acid facilitates the initiation of apoptosis by increasing cellular sensitivity to apoptotic stimuli including TNF and Fas ligand. ${ }^{31}$

Similar to galectin-1, galectin-3 also associates with Fas and controls the Fas signaling route. ${ }^{32}$ By forming a complex with the internal Fas domain, endogenous galectin-3 promotes DISC formation, caspase-8 recruitment and caspase-3 cleavage, whereas it represses apoptotic signals through the $\mathrm{C}_{2}$-ceramide. ${ }^{32}$ On the other hand, the antiapoptotic function of intracellular galectin-3 is associated with TRAIL activity. Expression of galectin-3 is significantly elevated in TRAIL-resistant bladder carcinoma cells and cooperates with phosphatidylinositol 3-kinase (PI3K)/Akt to increase tumor cell survival. ${ }^{33}$ In breast carcinoma, overexpression of galectin-3 induces inactivation of Akt possibly through redox-dependent mechanisms, thereby enhancing TRAIL-induced cytotoxicity. ${ }^{34}$ In contrast, galectin-1 has been proposed as a candidate inhibitor, which decreases Akt activity and induces apoptosis of breast cancer cells. ${ }^{35}$ Recently, Mazurek and co-workers ${ }^{36}$ documented a direct interaction between galectin-3 and TRAIL, further emphasizing the antiapoptotic properties of this lectin. When galectin-3 is expressed on colon cancer cells, it promotes the formation of a heterodimeric complex with TRAIL-R1 and TRAIL-R2 by anchoring these death receptors through glycosylation-dependent mechanisms. ${ }^{36}$ However, the antiapoptotic properties of galectin-3 are lost when this lectin is post-translationally modified by phosphorylation at serine $6 .{ }^{37}$ This phosphorylation event promotes sensitivity of breast cancer cells to TRAIL by enhancing extrinsic and intrinsic apoptotic pathways, inactivating PI3K/Akt survival pathway and stimulating the phosphatase activity ${ }^{38}$ (Figure 1a).

\section{Apoptosis Mediated by Lectin-Glycan Interactions through Death Receptor-Independent Mechanisms}

In addition to the classical death receptors, several transmembrane glycoproteins and lectin receptors can transduce intracellular signals leading to cell death.
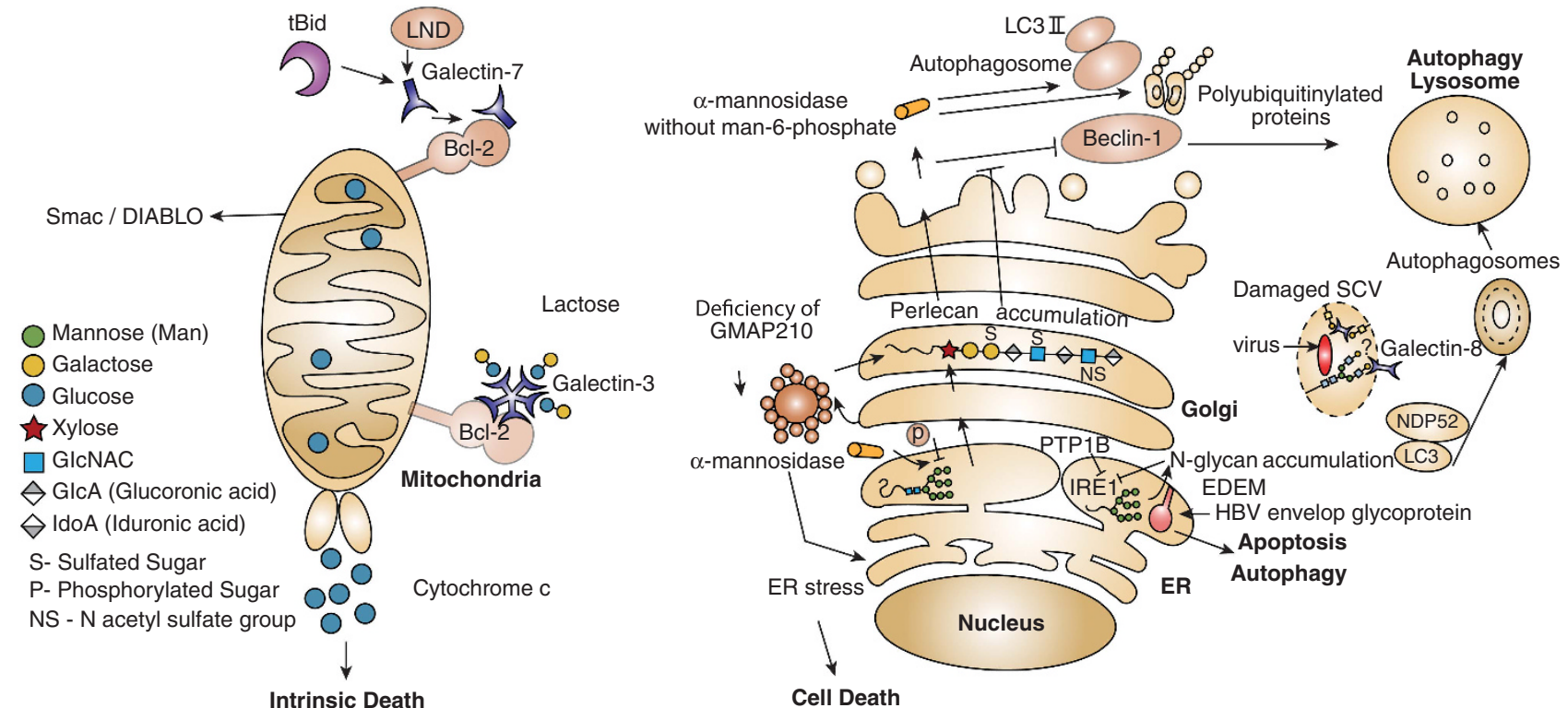

Figure 2 Glycans and glycan-binding proteins are integral components of the autophagy and apoptosis machineries. Interaction of galectins with various intracellular proteins either in a glycan-dependent or -independent manner may control cell death in diverse subcellular compartments. In tBid- or LND-treated mitochondria, as well as in untreated mitochondria, intracellular galectin-3 and galectin-7 form heterodimers with Bcl-2, which modulate cellular apoptosis. Galectin-7-Bcl-2 complex promotes release of cytochrome $c$ and Smac/DIABLO factors, facilitating the intrinsic death pathway. In contrast, endogenous galectin-8 is a cytoprotective intermediate protein that restrains Salmonella proliferation and inflammation by neutralizing bacteria-damaged SCV in human host cells. Host galectin-8 binds glycans expressed on the SCV, recruits and forms complexes with NDP52 and LC3, which lead to encapsulating SCV into an autophagosome. Finally, the unwanted cargo is degraded in the lysosome. It is not clear whether galectin-8 binds to $\mathrm{N}$-glycans or to $\mathrm{O}$-glycans of the SCV. The cargo proteins, mannosidase-like protein (EDEM) in the ER and hydrolase $\alpha$-mannosidase, as well as accumulation of $\mathrm{N}$-glycans in the ER are involved in cell death. Whereas EDEM facilitates the removal of envelope glycoprotein of hepatitis B virus (HBV)-infected cells in an autophagy-dependent manner, the absence of the phosphatase PTP-1B impairs EDEM transcription and suppresses apoptosis. Defective mannose-6 phosphate targeting mechanism impairs transportation of $\alpha$-mannosidase and of many glycan-metabolizing enzymes from the secretory pathway to the lysosome. Such impairment causes the accumulation of polyubiquitinylated protein aggregates and LC3-II and unchanged expression of Beclin-1, which together inhibit autophagy. Golgi architecture protein GMAP210 has been also involved in cell death signaling programs. Deficiency of this protein promotes ER stress accompanied by abnormal glycosylation, accumulation of perlican in the Golgi and cell death. Whether intermediates of Golgi glycosylation are involved in cell death is still not clear. tBid, truncated Bcl-2 homology-3 (BH3)-interacting domain death agonist; LND, lonidamine; Smac/DIABLO, second-mitochondria-derived activator of caspases; SCV, Salmonella-containing vacuole; EDEM, ER degradationenhancing $\alpha$-mannosidase-like protein; PTP-1B, protein-tyrosine phosphatase 1B; GMAP210, Golgi-associated microtubule-binding protein 210 


\section{Galectin Counter-Receptors in the Initiation of Cell Death}

Soluble galectins form multivalent complexes with a selected repertoire of glycosylated receptors, leading to a shift in the molecular composition of the receptor interactome. Clustering and segregation of CD45 with CD3 and CD7 with CD43 are crucial for initiating death following galectin-1 binding to T cells. ${ }^{39}$ The CD45 phosphatase mediates apoptosis through modulation of the extrinsic pathway affecting downstream signaling mechanisms after internalization into the cell. Upon engagement of CD45, both caspase-3 activation and cleavage of the DNA fragmentation factor DFF-40 occur. ${ }^{40}$ In response to galectin-1, activated $T$ cells downregulate the expression of the antiapoptotic B-cell lymphoma-2 downregulate the $(\mathrm{Bcl}-2)$ protein and activate effector caspases. ${ }^{41}$ Mechanistically, this lectin triggers endonuclease $\mathrm{G}$ nuclear translocation, ${ }^{42}$ p56/Lck tyrosine phosphorylation ${ }^{43}$ and activator protein-1 activation. ${ }^{44,45}$ Moreover, galectin-1 stimulates the release of ceramide and promotes c-Jun $\mathrm{N}$-terminal kinase (JNK) activation. As a result, Bcl-2 accumulation is condensed and $\mathrm{Bcl}-2$ phosphorylation is elevated, generating heterodimerization with the proapoptotic protein Bax. These molecular events lead to caspase- 3 and -9 activation resulting in T-cell death. ${ }^{45}$

Expression of core-2 O-glycans (Gal $\beta 1-3$ [ $N$-acetyl glucosamine] $\beta 1-6$ GalNAc) on the surface of $T$ cells allows clustering of CD45, which facilitates galectin-1-induced apoptosis. ${ }^{46}$ The absence of this glycan and particularly the presence of $\alpha 2-6$-linked sialic acid on CD45 N-glycans counteract inhibition of CD45 tyrosine phosphatase activity, which is an essential step in galectin-1-induced cell death. ${ }^{47}$ Interestingly, differential glycosylation of T-helper (Th) cell subsets selectively regulates susceptibility to cell death. In contrast to Th1 and Th17 cells, survival of Th2-polarized lymphocytes is controlled by $\alpha 2-6$ sialylation of cell surface glycoproteins, which adjusts the threshold for galectin-1 binding. ${ }^{48}$ However, binding of galectin-1 to CD45 or CD43 leads to apoptosis. This lectin binds to CD43 leading to dendritic cell migration and promotion of a regulatory phenotype. ${ }^{29,49}$ Moreover, galectin-1 binding to core-2 O-glycans on CD45 induces cell surface retention of this glycoprotein and amplification of CD45 phosphatase activity in microglial cells. This effect leads to the inhibition of the mitogen-activated protein kinase p38, cAMP response element binding and NF- $\kappa \mathrm{B}-$ dependent signaling, which ultimately prevent M1 microglia activation and promote neuroprotection. ${ }^{50}$ Thus, binding of galectin-1 to identical glycoproteins may result in different cellular outcomes depending on the particular target cell and the spatiotemporal regulation of glycosyltransferases, responsible for building the 'cellular glycome'.

Interestingly, glycosylation changes dramatically according to cellular activation and differentiation. For example, the contraction or resolution phase of $\mathrm{CD}^{+} \mathrm{T}$-cell responses is accompanied by the synthesis of extra core-2 0 -glycans and the concomitant loss of $\alpha 2-3$ sialylation of core-1 O-glycans. These events render activated $\mathrm{CD} 8^{+} \mathrm{T}$ cells susceptible to apoptosis even in Bcl-2-transgenic mice. ${ }^{51}$ In Bim-deficient mice however, removal of $\alpha 2-3$-linked sialic acid reduces the accumulation of $\mathrm{CD}^{+} \mathrm{T}$ cells without diminishing apoptosis. ${ }^{51}$ Unlike the mechanism of $\mathrm{CD}^{+}$T-cell homeostasis, $\mathrm{CD}^{+} \mathrm{T}$ cells interact with the macrophage galactose-type lectin, a C-type lectin receptor expressed on dendritic cells through binding to CD45, resulting in the reduction of CD45 phosphatase activity and induction of apoptosis. ${ }^{52}$

In contrast to intracellular galectin-3, which possesses antiapoptotic properties, secreted galectin-3 displays proapoptotic activity through binding to CD7 and CD29 $\left(\beta_{1} \text {-integrin }\right)^{53}$ or to CD45 and CD71. ${ }^{54}$ Crosslinking of CD7 and CD29 by galectin-3 results in cytochrome $c$ release and caspase-3 activation. Interestingly, intracellular galectin-3 can prevent apoptosis induced by galectin-1, most likely by stabilizing the mitochondria. ${ }^{42}$ However, the antiapoptotic effects of intracellular galectin-3 are attenuated by syntexin, a member of the annexin family, which prevents galectin-3 translocation to the perinuclear membrane and facilitates its secretion. ${ }^{55}$ Moreover, the proapoptotic activity of extracellular galectin-3 is modulated by the glycan composition of relevant receptors. Low $\alpha 2-6$ sialylation increases the affinity of galectin-3 to CD29, thereby amplifying cell death signals. ${ }^{56}$ Interestingly, $\alpha 2-6$ sialylation also showed significant effects on cancer immunoediting, a process in which cell death plays a critical role. ${ }^{57}$

An interesting example of how lectin-receptor interactions control inflammatory response has been shown for galectin-8. Binding of galectin-8 to CD44 activates the proapoptotic machinery in joint inflammatory cells and promotes relief of inflammation. This effect depended on the formation of multiprotein complexes that comprised of soluble CD44 and fibrinogen. ${ }^{58}$ Accordingly, delivery of galectin-1 to sites of inflammation promoted T-cell apoptosis and attenuated inflammation in different models of autoimmune disease. ${ }^{59}$ These findings emphasize the relevance of apoptosis as a therapeutic modality in chronic inflammatory conditions. Interestingly, the T-cell immunoglobulin mucin domain 3 (TIM-3) has been implicated in T-cell apoptosis. Binding of galectin-9 to TIM-3 triggers selective death of Th1 cells ${ }^{60}$ through $\mathrm{Ca}^{2+}$-calpain-caspase- 1 mechanisms. ${ }^{61}$ The proapoptotic effects of galectin-9 involve the formation of stable dimeric structures containing two carbohydrate recognition domains (CRDs) and require the presence of complex $\mathrm{N}$-glycans on target cells. ${ }^{62}$ Recent studies implicated the human leukocyte antigen B-associated transcript (Bat3) as a molecular adaptor linked to the intracellular tail of TIM-3, which protects Th1 cells from galectin-9-induced apoptosis. ${ }^{63}$ However, studies on TIM-3-galectin-9 interactions were so far based on exposure to exogenous galectin-9. Whether an additional ligand competes with galectin- 9 for TIM- 3 is less clear. In this regard, galectin-9-independent TIM-3 activity has been documented. ${ }^{64}$ More recently, a subset of TIM-3 and programmed death 1-positive FoxP3 ${ }^{+} \mathrm{T}$ regulatory cells, which was sensitive to galectin-9, has been found within graft-infiltrating T cells. ${ }^{65}$

Among the various glycoproteins that serve as binding partners for galectins, CD29 preferentially interacts with galectin-2, whereas CD3 selectively binds galectin-4. Upon binding to CD29, galectin-2 elicits apoptosis of activated $\mathrm{T}$ cells through mechanisms involving reduction of the mitochondrial transmembrane potential $(\Delta \psi \mathrm{m})$ and 
enhancement of cytochrome $c$ release subsequent to caspase- 3 and -9 activation. Galectin-2 triggers mitochondrial outer membrane permeabilization (MOMP) in activated $\mathrm{T}$ cells as documented by enhancement of the Bax to $\mathrm{Bcl}-2$ ratio. ${ }^{66}$ However, it is not clear whether galectin-2 or galectin2-activated $\mathrm{Bcl}-2$ homology-3 (BH3) stimulates MOMP by triggering oligomerization of $\mathrm{Bax}$ in the outer mitochondrial membrane, which forms channels to allow mitochondrial protein escape from the inner mitochondria. ${ }^{67}$ On the other hand, galectin-4 binding to CD3 promotes T-cell apoptosis through a calpain-sensitive but caspase-independent pathway. ${ }^{68}$ Although galectin- 2 and galectin-4 promote T-cell death in vitro, the physiologic relevance of these interactions in vivo remains uncertain.

\section{Endogenous Glycans and Lectins in the Execution of the Cell Death Programs}

The involvement of endogenous lectin-glycan recognition systems in cell death programs is illustrated in Figure 2. Intracellular galectins can fine-tune responses that amplify or attenuate execution of cell death triggered by a variety of stimuli. Here we discuss selected examples showing how interactions between intracellular galectins and their ligands can regulate cellular homeostasis (Table 1).

Intracellular galectin-7 is regarded as a p53-regulated proapoptotic protein expressed by stratified epithelia. ${ }^{69}$ Galectin-7 is overexpressed in apoptotic keratinocytes exposed to UV irradiation. ${ }^{70}$ Exposure to proapoptotic stimuli increases galectin-7 expression, which induces upregulation of caspase-3, augments cytochrome $c$ release and promotes JNK activation. ${ }^{69}$ Recently, analysis of the $\mathrm{Bcl}-2$ interactome identified galectin-7 as a mitochondrial Bcl-2-interacting protein in colon carcinoma cells. Following treatment of purified mitochondria with $\mathrm{tBid}$, a truncated $\mathrm{BH} 3$-interacting domain death agonist or with lonidamine, an activator of the mitochondrial transition-permeability pore opening, mitochondrial galectin-7 promoted the release of cytochrome $c$ and second mitochondria-activator of caspases (Smac)/DIABLO factors. This response was prevented when exogenous galectin-7 was added to cell cultures, suggesting that mitochondrial galectin-7-Bcl-2 heterodimers selectively enhance the intrinsic apoptotic pathway. ${ }^{71}$ In this regard, earlier studies have demonstrated the ability of intracellular galectins to interact with or mimic $\mathrm{Bcl}-2$ proteins to control apoptosis. Intracellular galectin-3 forms heterodimers with $\mathrm{BCl}-2^{72}$ similar to homologous proteins like Bax, ${ }^{73}$ suggesting a model in which the ratio of $\mathrm{Bcl}-2$ to intracellular galectin-3 dictates cell fate. As discussed earlier, intracellular galectin-3 displays antiapoptotic properties and its phosphorylation at serine 6 prevents the transmission of antiapoptotic signals. ${ }^{38}$ By contrast, phosphorylation at tyrosine 79 and tyrosine 118 by $\mathrm{c}-\mathrm{Abl}$ and Arg tyrosine kinases represses galectin-3 lysosomal-dependent degradation via the chaperone-mediated autophagy (CMA), and association of galectin- 3 with these kinases increases the antiapoptotic activity of this lectin. ${ }^{74}$ Thus, phosphorylation of intracellular galectin-3 serves as a regulatory mechanism to control selectively the apoptotic machinery.

\section{Glycosylation-Related Molecules are Integral Components of the Autophagy and Apoptosis Machineries}

Interestingly, the activity of glycosidases, including $\alpha$-galactosidase, $\alpha$-mannosidase and neuraminidase, is modulated by $\mathrm{c}$-Abl and Arg tyrosine kinases during autophagy in lysosomes, highlighting another cellular event in which the glycosylation machinery controls cell death programs. ${ }^{75}$ The main role of glycan-degrading enzymes in cellular autophagy was initially studied for $\alpha$-mannosidase in the yeast Saccharomyces cerevisiae. Under starvation conditions, $\alpha$-mannosidase acts as a selective cargo protein, trafficking from the cytosol to the vacuole (the yeast ortholog of mammalian lysosome) through a sequential mechanism involving assembly into an oligomer in the cytosol, sequestering into a double-membrane vesicle called autophagosome and fusing with the vacuole. After fusion, the autophagic content is released to the vacuolar lumen and the content is degraded by hydrolases. ${ }^{76}$ The selective transport of $\alpha$-mannosidase is promoted by the autophagy protein 34 (Atg34), which links the mannosidase to Atg8 (a yeast homolog of mammalian light chain-3; LC3) during autophagy. ${ }^{77,78}$ In mammalian cells, the trafficking of lysosomal $\alpha$-mannosidase to the lysosome after its synthesis in the ER-Golgi depends on the phosphorylation of mannose residues in high-mannose glycans. ${ }^{79}$ Recently, a study on type-II mucolipidosis, a neurometabolic lysosomal trafficking disorder of childhood, revealed accumulation of polyubiquitinylated protein aggregates like p62 and the vesicleassociated form LC3-II as well as unchanged expression of Beclin-1, which disarms the autophagic machinery of neuronal tissue as a result of impairment in the activity of lysosomal glycan-metabolizing enzymes. ${ }^{80}$

Endogenous galectin-8 participates in the intracellular cascades of autophagy. In damaged organelles and infected cells, galectin-8 has been defined as a sensor of nonspecific damage and an autophagy-inducing signal for eradicating bacterial infections. In vesicles of Salmonella-infected cells and following mechanical damage of the lysosomes and endosomes, glycans are exposed, facilitating binding of host galectin-8. In a setting of cellular infection, bound galectin-8 recruits and binds autophagic proteins including the nuclear dot protein $52 \mathrm{kDa}$ (NDP52) and LC3, as well as other components of the autophagy machinery, capturing the bacterium in the autophagosome, which is then destroyed in the lysosome by digestive enzymes. ${ }^{81} \mathrm{Li}$ and co-workers ${ }^{82}$ recently solved the crystal structure of the NDP52-galectin-8 complex showing that NDP52 selectively binds galectin-8 but not other galectins to restrict the growth of Salmonella in human cells. Thus, it appears that endogenous galectin- 8 is part of an innate defense mechanism in the cytosol that restricts bacterial replication and inflammation. In some cases, such a mechanism is similar to ER-stress-elicited autophagy, which is commonly cytoprotective.

The ER compartment is responsible for the quality control of newly synthesized proteins and glycoproteins. When a protein or glycoprotein is incorrectly folded, the ER-stress sensor (IRE1) initiates an ER-associated degradation (ERAD) pathway to degrade the misfolded protein by an array 
of proteins and enzymes, including the ER degradationenhancing $\alpha$-mannosidase-like protein (EDEM). ${ }^{83,84}$ ER stress is caused by the accumulation of misfolded proteins, impairment of $\mathrm{N}$-glycan biosynthesis and synthesis of central ER proteins, ${ }^{85}$ and is facilitated by infectious processes, ${ }^{86}$ which activate the IRE1-dependent pathway. Recent studies have shown direct and indirect involvement of EDEM in modulating apoptosis and autophagy. Repression of IRE1 signaling and suppression of apoptosis are events observed in the absence of the protein-tyrosine phosphatase (PTP)-1B, which impairs EDEM transcription, IRE1-dependent JNK activation and XBP-1 splicing. ${ }^{85}$ Similar to the cytoprotective function of galectin-8, EDEM in the ERAD process can facilitate the reduction of hepatitis envelope proteins in hepatitis B virus-infected cells in an autophagydependent manner with the purpose of protecting host cells. ${ }^{87}$ Accordingly, $\alpha$-mannosidase-like protein and the hydrolase share functions of controlling both apoptosis and autophagic cell death under the title of cargo proteins, although they differ in their intracellular localization. Whereas EDEM is concentrated in the ER, $\alpha$-mannosidase is distributed in the cytosol to form vacuoles (Cvt) or autophagosomes. ${ }^{77}$

ER stress can also be caused by impairment of Golgi proteins. In this respect, Smits and co-workers ${ }^{88}$ showed that in vivo deficiency of Golgi-associated microtubule-binding protein 210 (GMAP-210) increased death of chondrocytes and other cells in the humerus and ulna cells during skeletal development. GMAP-210 is one of the proteins tethering vesicles to the Golgi and maintaining its architecture. ${ }^{89}$ Deficiency of GMAP-210 alters glycosylation in the Golgi of chondrocytes and fibroblasts, promoting accumulation of the proteoglycan perlican, which is a hallmark of patients with achondrogenesis. ${ }^{88}$ Although disassembly of Golgi apparatus during apoptosis is well documented, ${ }^{90,91}$ the involvement of GMAP-210 in the abnormal synthesis of glycosylated molecules and cell death represents the first evidence associating the Golgi apparatus with the initiation of a stress response. Whether components of the glycosylation machinery may serve as intermediates of cell death in the Golgi apparatus remains an open question.

\section{Glycans and Lectins in the Resolving Stages of Cell Death}

Removal of apoptotic cells involves the sequential action of multiple steps, through which phagocytes selectively recognize and engulf apoptotic cells. These include the activity of specific chemoattractants, which assist phagocytes to sense dying cells ${ }^{92}$ ('find me' signals) and mechanisms involved in the engulfment of dying cells ('eat me' signals). Lectin-glycan recognition systems have been identified as part of the apoptosis-resolving machinery (Figure 3 and Table 1).

Among the biological activities displayed by galectin-3, this lectin serves as a selective chemoattractant for monocytes and macrophages ${ }^{93}$ and promotes phagocytosis of apoptotic thymocytes, ${ }^{94,95}$ suggesting a role for this lectin as a 'find me' signal for these cell types. While extracellular galectin-3 contributes to macrophage recruitment, intracellular galectin3 contributes to apoptotic cell clearance. ${ }^{94}$ Conversely, the offset of 'find me' signals is the 'keep out' or 'don't find me' signals, which are sent out by dying cells and negatively regulate phagocyte recruitment. For example, the $80 \mathrm{kDa}$ glycoprotein lactoferrin operates as a negative regulator released by dying cells to halt neutrophil migration in response to chemokines in the apoptotic milieu. ${ }^{96}$ As intelectin-1, a C-type lectin that binds galactose and GalNAc residues acts as a receptor for lactoferrin on phagocytes, ${ }^{97}$ the involvement of lectin-glycan interactions in mediating 'keep-out' signals remains to be determined.

In the second phase, 'eat me' signals displayed by apoptotic cells promote the recognition of dying cells and the initiation of phagocytosis. Glycans and lectins have a professional role in the recognition of infected apoptotic cells. A prominent player of these late apoptotic events is the ER chaperone calreticulin (CRT) expressed on apoptotic cells. Calreticulin is a lectin specific for monoglucosylated $\mathrm{N}$-glycans, which participates in the quality control of protein/glycoprotein folding. CRT acts as a coreceptor for opsonin $\mathrm{C} 1 \mathrm{q}$ and as an endocytic pattern recognition receptor on macrophages. ${ }^{98}$ Similarly, soluble pattern recognition glycan-binding proteins such as ficolin-2, ficolin-3 and collectins contribute to clearance of dying cells. ${ }^{99}$ For example, the surfactant protein A, a lung collectin, recognizes apoptotic neutrophils as inflammation resolves and mediates phagocytosis by alveolar macrophages. ${ }^{100}$

Another interesting opsonin recently proposed to be involved in apoptotic neutrophil clearance is galectin-3, which interacts with Mer receptor tyrosine kinase (MerTK) to facilitate MerTK-mediated phagocytosis. ${ }^{101}$ Nevertheless, galectin-3 does not exclusively function as a chemoattractant or bridging ligand in phagocytosis. This galectin, as well as galectin-1 and galectin-4, are prominent inducers of phosphatidylserine exposure, a common 'eat me' signal recognized by phagocytic receptors on the surface of apoptotic cells. Galectin-1, galectin-3 and galectin-8 enhance phosphatidylserine exposure on activated neutrophils and myeloid HL-60 cells, whereas galectin- 2 and galectin-4 induce the same effect on activated T lymphocytes. In both cell types, exposure to soluble galectins promotes phosphatidylserine exposure without engaging a full apoptotic program. ${ }^{102-104}$

Interestingly, other 'eat me' signals may function together with phosphatidylserine with the common aim of executing phagocytosis. ${ }^{105}$ Engulfment depends on particular phagocytic receptors used to ingest apoptotic cells. ${ }^{106}$ This is clearly illustrated by studies showing how phagocytes clear circulating activated platelets as a way of dampening vascular inflammation. Although activated platelets express phosphatidylserine, clearance is initiated by interaction between the tethering lectin, P-selectin on activated platelets and the sialyl-Lewis ${ }^{x}$ glycan epitope on P-selectin glycoprotein ligand-1 expressed on resting neutrophils. As a consequence, neutrophils release granules and upregulate $\beta_{2}$-integrins, which stabilize adhesion to activated platelets. Finally, neutrophils engulf the tethered platelets and confine them into phagosomes. ${ }^{107}$ Other studies illustrate the formation of a multiprotein complex with phosphatidylserine that is essential to execute phagocytosis. The macrophage-secreted glycoprotein, milk fat globule-EGF-factor 8 (MFG-E8), binds to phosphatidylserine on apoptotic cells before cell engulfment. ${ }^{108,109}$ Recent studies showed that TIM-4 expressed by phagocytes forms a complex with phosphatidylserine on apoptotic pro-B cells as a first event in the promotion of 


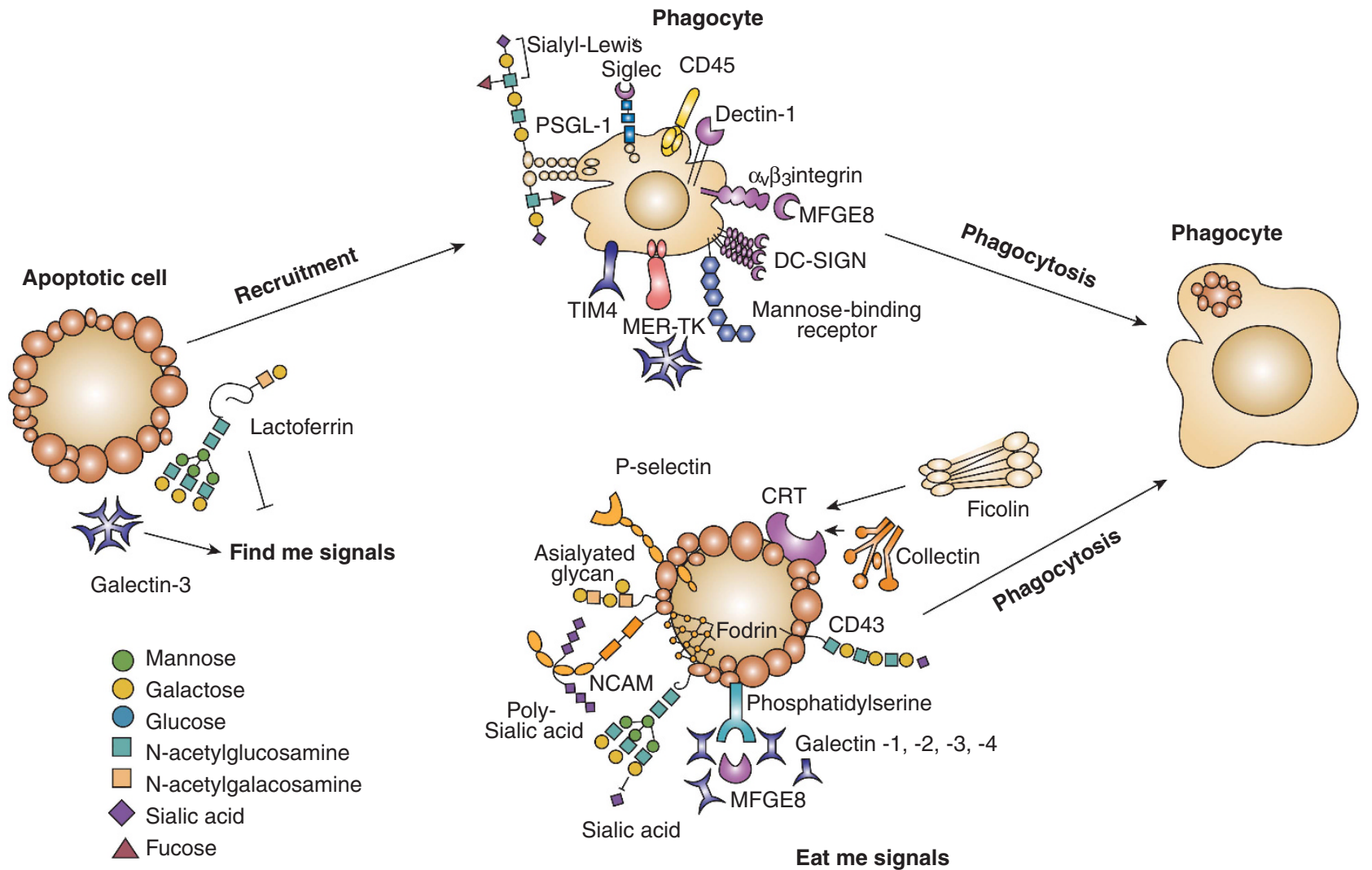

Figure 3 Glycans and lectins in the resolving stages of cell death. Removal of apoptotic cells involves 'find me' signals, 'eat me' signals and engulfment of dying cells by phagocytes. Selected lectin-glycan recognition systems, which have been identified as part of that apoptotic cell removal, are shown. Among the 'find me' and 'eat me' signals illustrated, galectins and soluble glycoproteins are involved in the initiation of phagocytosis and tethering. Galactose-terminated glycans and also poly-sialic acids act as 'eat me' signals, whereas sialy-Lewis ${ }^{\mathrm{x}}$ terminal groups have been involved in tethering. P-selectin and calreticulin displayed on apoptotic cells have essential roles in the initiation of phagocytosis and C-type lectins and siglecs have been implicated in tethering. TIM-4, T-cell immunoglobulin mucin-4; PSGL-1, P-selectin glycoprotein ligand-1; DC-SIGN, dendritic cell-specific intracellular adhesion molecule-3-garbbing non-integrin; NCAM, neural cell adhesion molecule

phagocytosis. As a result, $\alpha_{\mathrm{V}} \beta_{3}$-integrin is activated and forms a complex with MFG-E8, which also binds to phosphatidylserine, allowing apoptotic cell uptake. ${ }^{110}$ Also, CD45mediated death of $T$ cells via galectin- 1 requires the presence of fodrin, a cytoskeletal linker molecule that attaches CD45 to the actin cytoskeleton. Degradation of fodrin is essential to accelerate uptake of apoptotic cells by macrophages. ${ }^{111}$

In addition, glycans also participate as 'eat me' signals for apoptotic cells. Specifically, a low content of sialic acid in apoptotic cells serves as an 'eat me' signal in different cell types, including HeLa cells infected with influenza virus $A .{ }^{112}$ Also, reduced amounts of terminal $\alpha 2-6$ - and $\alpha 2-3-$ linked sialic acid on apoptotic $T$ cells favor their engulfment by phagocytes. ${ }^{113}$ In addition, Gal $\beta 1$-3GalNAc-enriched glycoepitopes on apoptotic bodies have been identified as 'eat me' signals, allowing clearance of dying cells by macrophages. ${ }^{114}$ Phagocytes can interact with sialyl-poly-lactosaminyl glycans on the bridging receptor CD43 expressed on apoptotic T cells and promote their phagocytosis. ${ }^{115}$

The mechanisms underlying changes in the 'apoptotic cell glycome' and their link to phagocytosis remain elusive. It is possible that glycan-modified proteins in apoptotic cells first bind filaments, that is, vimentin-like lectins, ${ }^{116}$ siglecs (e.g. siglec-5) ${ }^{117}$ or $\mathrm{C}$-type lectin receptors ${ }^{118}$ on neighboring phagocytes. In the case of vimentin, the interactions with apoptotic cells promote phosphorylation of filaments, which disassemble them and recruit tetramers to the cell surface. Tetramers facilitate the engulfment of apoptotic cells. ${ }^{116}$ Alternatively, fluctuations in cell surface glycosylation may regulate the balance of 'eat me' and 'don't eat me' signals, with critical implications in corpse uptake.

On the other hand, inhibitory siglecs reduce phagocytosis when they form complexes with sialic acid-containing ligands. For example, Siglec-5 facilitates infection through binding to sialic acid present on the streptococcus $\beta$-protein, an effect that impairs phagocytosis. ${ }^{119}$ Moreover, Siglec 11 expressed on the surface of microglia cells binds polysialic acid on neuron's NCAM and suppresses phagocyte activation. ${ }^{120}$ Hence, the picture that has emerged is that siglecs can modulate clearance of dying cells through glycosylation-dependent 'self/non-self' recognition.

The engulfment of apoptotic cells is facilitated by the presence of many receptors expressed on scavenger cells, some of which were previously specified as 'eat me' signals. Additional lectin receptors such as DC-SIGN and mannosebinding receptor are upregulated on macrophages and dendritic cells and have been proposed to participate in the removal of human apoptotic thymocytes. ${ }^{121}$ In line with 
this finding, Dectin-1, another C-type lectin receptor, has been reported to sense and phagocytose apoptotic tumor cells. ${ }^{118}$ Furthermore, scavenger cells expressing these lectin receptors can ingest apoptotic cells and act as antigen-presenting cells (APCs) presenting epitopes derived from ingested apoptotic cells to effector T cells. It is worth noting that APCs engulfing apoptotic cells can secrete soluble mediators and cytokines capable of activating or blunting adaptive immune responses. ${ }^{118,122}$ Thus, silent clearance of 'unwanted-self' or 'dangerous' immune cells, via lectin-glycan interactions, represents an evolutionarily conserved homeostatic mechanisms to reduce or prevent exuberant inflammatory responses.

\section{Conclusions and Future Directions}

The study of the cellular glycome has provided new insights into a variety of physiologic processes. Interactions between endogenous lectins and glycans can set the threshold for cellular activation, differentiation and survival. Here, we discuss the relevance of lectin-glycan recognition systems in the initiation, execution and resolution of cell death and provide selected examples that illustrate their important roles in these processes. While differential glycosylation of death receptors controls the transmission of lethal signals, soluble or cell surface-associated glycan-binding proteins can initiate apoptotic programs indirectly by interacting with death receptors or directly by crosslinking a myriad of cell surface glycoproteins. In addition, intracellular galectins and glycanmodifying enzymes have important roles in the execution of cell death programs including apoptosis and autophagy. These intracellular galectins and glycan-modifying enzymes not only orchestrate degradation of self or foreign cargo in response to cellular damage and infection but also control immune responses and inflammation. Moreover, incorrect glycan presentation alters autophagy, which contributes to disease severity. Finally, endogenous lectins and glycans can serve as 'find me', 'keep out' and 'eat me' signals in the resolution of apoptosis. The current wealth of information allows the visualization of strategies through which manipulation of lectin-glycan recognition systems may contribute to the control of cell death programs with critical implications in the resolution of inflammation, chronic infection, autoimmunity, neurodegeneration and cancer.

\section{Conflict of Interest}

The authors declare no conflict of interest.

Acknowledgements. We apologize to the many authors whose excellent papers could not be cited because of space limitations. We thank Dr. Helene Rosenberg for critical reading of the manuscript. Research in authors' laboratory is supported by grants from the National Multiple Sclerosis Society (USA), Prostate Action (UK), National Agency for Promotion of Science and Technology (Argentina), University of Buenos Aires (Argentina), National Council of Scientific and Technical Investigations (CONICET, Argentina) and Fundación Sales (Argentina) to GAR and Ministry of Industry, Trade and Labor (Israel) and Ministry of Science and Technology (Israel) to RGL.

1. Lockshin RA, Williams CM. Programmed cell death-I. Cytology of degeneration in the intersegmental muscles of the pernyi silkmoth. J Insect Physiol 1965; 11: 123-133.
2. Kerr JF, Wyllie AH, Currie AR. Apoptosis: a basic biological phenomenon with wide-ranging implications in tissue kinetics. Br J Cancer 1972; 26: 239-257.

3. Sharon $\mathrm{N}$, Lis $\mathrm{H}$. History of lectins: from hemagglutinins to biological recognition molecules. Glycobiology 2004; 14: 53R-62R.

4. Morris RG, Hargreaves AD, Duvall E, Wyllie AH. Hormone-induced cell death. 2 Surface changes in thymocytes undergoing apoptosis. Am J Pathol 1984; 115: 426-436.

5. Duvall E, Wyllie AH, Morris RG. Macrophage recognition of cells undergoing programmed cell death (apoptosis). Immunology 1985; 56: 351-358.

6. Griffiths GD, Leek MD, Gee DJ. The toxic plant proteins ricin and abrin induce apoptotic changes in mammalian lymphoid tissues and intestine. J Pathol 1987; 151: 221-229.

7. Wesselborg S, Kabelitz D. Activation-driven death of human T cell clones: time course kinetics of the induction of cell shrinkage, DNA fragmentation, and cell death. Cell Immunol 1993; 148: 234-241.

8. Büssing A, Suzart K, Bergmann J, Pfüller U, Schietzel M, Schweizer K. Induction of apoptosis in human lymphocytes treated with Viscum album L. is mediated by the mistletoe lectins. Cancer Lett 1996; 99: 59-72.

9. Fu LL, Zhou CC, Yao S, Yu JY, Liu B, Bao JK. Plant lectins: targeting programmed cell death pathways as antitumor agents. Int J Biochem Cell Biol 2011; 43: 1442-1449.

10. Rabinovich GA. Galectins: an evolutionarily conserved family of animal lectins with multifunctional properties; a trip from the gene to clinical therapy. Cell Death Differ 1999 6: $711-721$.

11. Rabinovich GA, Croci DO. Regulatory circuits mediated by lectin-glycan interactions in autoimmunity and cancer. Immunity 2012; 36: 322-335.

12. Liu FT, Yang RY, Hsu DK. Galectins in acute and chronic inflammation. Ann N Y Acad Sci 2012; 1253: 80-91.

13. Brewer CF, Miceli MC, Baum LG. Clusters, bundles, arrays and lattices: novel mechanisms for lectin-saccharide-mediated cellular interactions. Curr Opin Struct Biol 2002; 12: 616-623.

14. Vasta GR. Galectins as pattern recognition receptors: structure, function, and evolution. Adv Exp Med Biol 2012; 946: 21-36.

15. Marth JD, Grewal PK. Mammalian glycosylation in immunity. Nat Rev Immunol 2008; 8: 874-887.

16. Hernandez JD, Baum LG. Ah, sweet mystery of death! Galectins and control of cell fate. Glycobiology 2002; 12: 127R-136R.

17. Fuster MM, Esko JD. The sweet and sour of cancer: glycans as novel therapeutic targets Nat Rev Cancer 2005; 5: 526-542.

18. Wagner KW, Punnoose EA, Januario T, Lawrence DA, Pitti RM, Lancaster $\mathrm{K}$ et al. Death-receptor O-glycosylation controls tumor-cell sensitivity to the proapoptotic ligand Apo2L/TRAIL. Nat Med 2007; 13: 1070-1077.

19. Moriwaki K, Noda K, Furukawa Y, Ohshima K, Uchiyama A, Nakagawa T et al. Deficiency of GMDS leads to escape from NK cell-mediated tumor surveillance through modulation of TRAIL signaling. Gastroenterology 2009; 137: 188-198.

20. Moriwaki K, Shinzaki S, Miyoshi E. GDP-mannose-4,6-dehydratase (GMDS) deficiency renders colon cancer cells resistant to tumor necrosis factor-related apoptosis-inducing ligand (TRAIL) receptor- and CD95-mediated apoptosis by inhibiting complex II formation. J Biol Chem 2011; 286: 43123-43133.

21. Shatnyeva OM, Kubarenko AV, Weber CE, Pappa A, Schwartz-Albiez R, Weber AN et al. Modulation of the CD95-induced apoptosis: the role of CD95 N-glycosylation. PLoS One 2011; 6: e19927.

22. Charlier E, Condé C, Zhang J, Deneubourg L, Di Valentin E, Rahmouni S et al. SHIP-1 inhibits CD95/APO-1/Fas-induced apoptosis in primary T lymphocytes and T leukemic cells by promoting CD95 glycosylation independently of its phosphatase activity. Leukemia 2010; 24: 821-832.

23. Dall'Olio F, Chiricolo M. Sialyltransferases in cancer. Glycoconj J 2001; 18: 841-850.

24. Peter ME, Hellbardt S, Schwartz-Albiez R, Westendorp MO, Walczak H, Moldenhauer G et al. Cell surface sialylation plays a role in modulating sensitivity towards APO-1-mediated apoptotic cell death. Cell Death Differ 1995; 2: 163-171.

25. Keppler OT, Peter ME, Hinderlich S, Moldenhauer G, Stehling P, Schmitz I et al. Differential sialylation of cell surface glycoconjugates in a human $B$ lymphoma cell line regulates susceptibility for CD95 (APO-1/Fas)-mediated apoptosis and for infection by a lymphotropic virus. Glycobiology 1999; 9: 557-569.

26. Swindall AF, Bellis SL. Sialylation of the Fas death receptor by ST6Gal-I provides protection against Fas-mediated apoptosis in colon carcinoma cells. J Biol Chem 2011 286: 22982-22990.

27. Schneider P, Bodmer JL, Holler N, Mattmann C, Scuderi $P$, Terskikh A et al. Characterization of Fas (Apo-1, CD95)-Fas ligand interaction. J Biol Chem 1997; 272 18827-18833

28. Abrahams VM, Straszewski SL, Kamsteeg M, Hanczaruk B, Schwartz PE, Rutherford TJ et al. Epithelial ovarian cancer cells secrete functional Fas ligand. Cancer Res 2003; 63: 5573-5581.

29. Rabinovich GA, llarregui JM. Conveying glycan information into T-cell homeostatic programs: a challenging role for galectin-1 in inflammatory and tumor microenvironments. Immunol Rev 2009; 230: 144-159.

30. Matarrese P, Tinari A, Mormone E, Bianco GA, Toscano MA, Ascione B et al. Galectin-1 sensitizes resting human $T$ lymphocytes to Fas (CD95)-mediated cell death via mitochondrial hyperpolarization, budding, and fission. J Biol Chem 2005; 280: 6969-6985. 
31. Liu Z, Swindall AF, Kesterson RA, Schoeb TR, Bullard DC, Bellis SL. ST6Gal-I regulates macrophage apoptosis via $\alpha 2-6$ sialylation of the TNFR1 death receptor. J Biol Chem 2011; 286: 39654-3962.

32. Fukumori T, Takenaka $\mathrm{Y}$, Oka N, Yoshii T, Hogan V, Inohara $\mathrm{H}$ et al. Endogenous galectin-3 determines the routing of CD95 apoptotic signaling pathways. Cancer Res 2004; 64: 3376-3379.

33. Oka N, Nakahara S, Takenaka Y, Fukumori T, Hogan V, Kanayama HO et al. Galectin-3 inhibits tumor necrosis factor-related apoptosis-inducing ligand-induced apoptosis by activating Akt in human bladder carcinoma cells. Cancer Res 2005; 65 : $7546-7553$

34. Lee YJ, Song YK, Song JJ, Siervo-Sassi RR, Kim HR, Li L et al. Reconstitution of galectin-3 alters glutathione content and potentiates TRAlL-induced cytotoxicity by dephosphorylation of Akt. Exp Cell Res 2003; 288: 21-34

35. Wells V, Mallucci L. Phosphoinositide 3-kinase targeting by the beta galactoside binding protein cytokine negates akt gene expression and leads aggressive breast cancer cells to apoptotic death. Breast Cancer Res 2009; 11: R2.

36. Mazurek N, Byrd JC, Sun Y, Hafley M, Ramirez K, Burks J et al. Cell-surface galectin-3 confers resistance to TRAIL by impeding trafficking of death receptors in metastatic colon adenocarcinoma cells. Cell Death Differ 2012; 19: 523-533.

37. Mazurek N, Conklin J, Byrd JC, Raz A, Bresalier RS. Phosphorylation of the betagalactoside-binding protein galectin-3 modulates binding to its ligands. J Biol Chem 2000 275: 36311-36315

38. Mazurek N, Sun YJ, Liu KF, Gilcrease MZ, Schober W, Nangia-Makker $P$ et al. Phosphorylated galectin-3 mediates tumor necrosis factor-related apoptosis-inducing ligand signaling by regulating phosphatase and tensin homologue deleted on chromosome 10 in human breast carcinoma cells. J Biol Chem 2007; 282: 21337-21348.

39. Pace KE, Lee C, Stewart PL, Baum LG. Restricted receptor segregation into membrane microdomains occurs on human $T$ cells during apoptosis induced by galectin-1. J Immunol 1999; 163: 3801-3811.

40. Desharnais P, Dupéré-Minier G, Hamelin C, Devine P, Bernier J. Involvement of CD45 in DNA fragmentation in apoptosis induced by mitochondrial perturbing agents. Apoptosis 2008; 13: 197-212.

41. Rabinovich GA, Ramhorst RE, Rubinstein N, Corigliano A, Daroqui MC, Kier-Joffé EB et al. Induction of allogenic T-cell hyporesponsiveness by galectin-1-mediated apoptotic and nonapoptotic mechanisms. Cell Death Differ 2002; 9: 661-670.

42. Hahn HP, Pang M, He J, Hernandez JD, Yang RY, Li LY et al. Galectin-1 induces nuclear translocation of endonuclease $\mathrm{G}$ in caspase- and cytochrome $c$-independent $\mathrm{T}$ cell death Cell Death Differ 2004; 11: 1277-1286.

43. Ion G, Fajka-Boja R, Tóth GK, Caron M, Monostori E. Role of p56lck and ZAP70mediated tyrosine phosphorylation in galectin-1-induced cell death. Cell Death Diffe 2005; 12: 1145-1147.

44. Rabinovich GA, Alonso CR, Sotomayor CE, Durand S, Bocco JL, Riera CM. Molecular mechanisms implicated in galectin-1-induced apoptosis: activation of the AP-1 transcription factor and downregulation of Bcl-2. Cell Death Differ 2000; 7 747-753.

45. Brandt $B$, Abou-Eladab EF, Tiedge M, Walzel H. Role of the JNK/c-Jun/AP-1 signaling pathway in galectin-1-induced T-cell death. Cell Death Dis 2010; 1: e23.

46. Nguyen JT, Evans DP, Galvan M, Pace KE, Leitenberg D, Bui TN et al. CD45 modulates galectin-1-induced T cell death: regulation by expression of core 20 -glycans. $J$ Immuno 2001; 167: 5697-5707.

47. Earl LA, Bi S, Baum LG. $N$ - and O-glycans modulate galectin-1 binding, CD45 signaling, and $T$ cell death. J Biol Chem 2010; 285: 2232-2244.

48. Toscano MA, Bianco GA, llarregui JM, Croci DO, Correale J, Hernandez JD et al. Differential glycosylation of $\mathrm{TH} 1, \mathrm{TH} 2$ and $\mathrm{TH}-17$ effector cells selectively regulates susceptibility to cell death. Nat Immunol 2007; 8: 825-834.

49. Fulcher JA, Chang MH, Wang S, Almazan T, Hashimi ST, Eriksson AU et al. Galectin-1 co-clusters CD43/CD45 on dendritic cells and induces cell activation and migration through Syk and protein kinase C signaling. J Biol Chem 2009; 284: 26860-26870.

50. Starossom SC, Mascanfroni ID, Imitola J, Cao L, Raddassi K, Hernandez SF et al. Galectin-1 deactivates classically activated microglia and protects from inflammationinduced neurodegeneration. Immunity 2012; 37: 249-263.

51. Van Dyken SJ, Green RS, Marth JD. Structural and mechanistic features of protein O glycosylation linked to CD8 + T-cell apoptosis. Mol Cell Biol 2007; 27: 1096-1111.

52. Van Vliet SJ, Gringhuis SI, Geijtenbeek TB, van Kooyk Y. Regulation of effector T cells by antigen-presenting cells via interaction of the C-type lectin MGL with CD45. Nat Immunol 2006; 7: 1200-1208.

53. Fukumori T, Takenaka Y, Yoshii T, Kim HR, Hogan V, Inohara H et al. CD29 and CD7 mediate galectin-3-induced type II T-cell apoptosis. Cancer Res 2003; 63: 8302-8311.

54. Stillman BN, Hsu DK, Pang M, Brewer CF, Johnson P, Liu FT et al. Galectin-3 and galectin-1 bind distinct cell surface glycoprotein receptors to induce $T$ cell death J Immunol 2006; 176: 778-789.

55. Yu F, Finley RL Jr, Raz A, Kim HR. Galectin-3 translocates to the perinuclear membranes and inhibits cytochrome $c$ release from the mitochondria. A role for synexin in galectin- 3 translocation. J Biol Chem 2002; 277: 15819-15827.

56. Zhuo Y, Chammas R, Bellis SL. Sialylation of beta1 integrins blocks cell adhesion to galectin-3 and protects cells against galectin-3-induced apoptosis. J Biol Chem 2008; 283: 22177-22185.
57. Cohen M, Elkabets M, Perlmutter M, Porgador A, Voronov E, Apte RN et al. Sialylation of 3-methylcholanthrene-induced fibrosarcoma determines antitumor immune responses during immunoediting. J Immunol 2010; 185: 5869-5878.

58. Eshkar Sebban L, Ronen D, Levartovsky D, Elkayam O, Caspi D, Aamar S et al. The involvement of CD44 and its novel ligand galectin-8 in apoptotic regulation of autoimmune inflammation. J Immunol 2007; 179: 1225-1235.

59. Rabinovich GA, Toscano MA. Turning 'sweet' on immunity: galectin-glycan interactions in immune tolerance and inflammation. Nat Rev Immunol 2009; 9: 338-352.

60. Zhu C, Anderson AC, Schubart A, Xiong H, Imitola J, Khoury SJ et al. The Tim-3 ligand galectin-9 negatively regulates $T$ helper type 1 immunity. Nat Immunol 2005; 6: $1245-1252$.

61. Kashio Y, Nakamura K, Abedin MJ, Seki M, Nishi N, Yoshida N et al. Galectin-9 induces apoptosis through the calcium-calpain-caspase-1 pathway. J Immunol 2003; 170: 3631-3636.

62. Lu LH, Nakagawa R, Kashio Y, Ito A, Shoji H, Nishi N et al. Characterization of galectin-9induced death of Jurkat T cells. J Biochem 2007; 141: 157-172.

63. Rangachari M, Zhu C, Sakuishi K, Xiao S, Karman J, Chen A et al. Bat3 promotes T cell responses and autoimmunity by repressing Tim-3-mediated cell death and exhaustion. Nat Med 2012; 18: 1394-1400.

64. Cao E, Zang X, Ramagopal UA, Mukhopadhaya A, Fedorov A, Fedorov E et al. T cell immunoglobulin mucin-3 crystal structure reveals a galectin-9-independent ligand-binding surface. Immunity 2007; 26: 311-321.

65. Gupta S, Thornley TB, Gao W, Larocca R, Turka LA, Kuchroo VK et al. Allograft rejection is restrained by short-lived TIM-3 + PD-1 + Foxp3 + Tregs. J Clin Invest 2012; 122: 2395-2404.

66. Sturm A, Lensch M, André S, Kaltner H, Wiedenmann B, Rosewicz S et al. Human galectin-2: novel inducer of $\mathrm{T}$ cell apoptosis with distinct profile of caspase activation. J Immunol 2004; 173: 3825-3837.

67. Paclik D, Danese S, Berndt U, Wiedenmann B, Dignass A, Sturm A. Galectin-4 controls intestinal inflammation by selective regulation of peripheral and mucosal $\mathrm{T}$ cell apoptosis and cell cycle. PLoS One 2008; 3: e2629.

68. Maiuri MC, Zalckvar E, Kimchi A, Kroemer G. Self-eating and self-killing: crosstalk between autophagy and apoptosis. Nat Rev Mol Cell Biol 2007; 8: 741-752.

69. Kuwabara I, Kuwabara Y, Yang RY, Schuler M, Green DR, Zuraw BL et al. Galectin-7 (PIG1) exhibits pro-apoptotic function through JNK activation and mitochondrial cytochrome c release. J Biol Chem 2002; 277: 3487-3497.

70. Bernerd F, Sarasin A, Magnaldo T. Galectin-7 overexpression is associated with the apoptotic process in UVB-induced sunburn keratinocytes. Proc Natl Acad Sci USA 1999; 96: 11329-1134.

71. Villeneuve C, Baricault L, Canelle L, Barboule N, Racca C, Monsarrat B et al. Mitochondrial proteomic approach reveals galectin-7 as a novel BCL-2 binding protein in human cells. Mol Biol Cell 2011; 22: 999-1013.

72. Yang RY, Hsu DK, Liu FT. Expression of galectin-3 modulates T-cell growth and apoptosis. Proc Natl Acad Sci USA 1996; 93: 6737-6742.

73. Oltvai ZN, Milliman CL, Korsmeyer SJ. Bcl-2 heterodimerizes in vivo with a conserved homolog, Bax, that accelerates programmed cell death. Cell 1993; 74: 609-619.

74. Li X, Ma Q, Wang J, Liu X, Yang Y, Zhao H et al. c-Abl and Arg tyrosine kinases regulate lysosomal degradation of the oncoprotein Galectin-3. Cell Death Differ 2010; 17: 1277-1287.

75. Yogalingam G, Pendergast AM. Abl kinases regulate autophagy by promoting the trafficking and function of lysosomal components. J Biol Chem 2008; 283: 35941-35953.

76. Hutchins MU, Klionsky DJ. Vacuolar localization of oligomeric alpha-mannosidase requires the cytoplasm to vacuole targeting and autophagy pathway components in Saccharomyces cerevisiae. J Biol Chem 2001; 276: 20491-20498.

77. Suzuki K, Kondo C, Morimoto M, Ohsumi Y. Selective transport of alpha-mannosidase by autophagic pathways: identification of a novel receptor, Atg34p. J Biol Chem 2010; 285: 30019-30025.

78. Watanabe Y, Noda NN, Kumeta H, Suzuki K, Ohsumi Y, Inagaki F. Selective transport of alpha-mannosidase by autophagic pathways: structural basis for cargo recognition by Atg19 and Atg34. J Biol Chem 2010; 285: 30026-30033.

79. Gabel CA, Goldberg DE, Kornfeld S. Lysosomal enzyme oligosaccharide phosphorylation in mouse lymphoma cells: specificity and kinetics of binding to the mannose 6-phosphate receptor in vivo. J Cell Biol 1982: 95: 536-542.

80. Kollmann K, Damme M, Markmann S, Morelle W, Schweizer M, Hermans-Borgmeyer I et al. Lysosomal dysfunction causes neurodegeneration in mucolipidosis II 'knock-in' mice. Brain 2012; 135: 2661-2675.

81. Thurston TL, Wandel MP, von Muhlinen N, Foeglein A, Randow F. Galectin 8 targets damaged vesicles for autophagy to defend cells against bacterial invasion. Nature 2012; 482: 414-418.

82. Li S, Wandel MP, Li F, Liu Z, He C, Wu J et al. Sterical hindrance promotes selectivity of the autophagy cargo receptor NDP52 for the danger receptor galectin-8 in antibacterial autophagy. Sci Signal 2013; 6: ra9.

83. Molinari M, Calanca V, Galli C, Lucca P, Paganetti P. Role of EDEM in the release of misfolded glycoproteins from the calnexin cycle. Science 2003; 299: $1397-1400$.

84. Oda Y, Hosokawa N, Wada I, Nagata K. EDEM as an acceptor of terminally misfolded glycoproteins released from calnexin. Science 2003; 299: 1394-1397. 
105. Fadok VA, Bratton DL, Frasch SC, Warner ML, Henson PM. The role of phosphatidylserine in recognition of apoptotic cells by phagocytes. Cell Death Differ 1998; 5: 551-562.

106. Arur S, Uche UE, Rezaul K, Fong M, Scranton V, Cowan AE et al. Annexin I is an endogenous ligand that mediates apoptotic cell engulfment. Dev Cell 2003; 4 587-598.

107. Maugeri N, Rovere-Querini P, Evangelista V, Covino C, Capobianco A, Bertilaccio MT et al. Neutrophils phagocytose activated platelets in vivo: a phosphatidylserine, P-selectin, and \{beta\}2 integrin-dependent cell clearance program. Blood 2009; 113: 5254-5265.

108. Hanayama R, Tanaka M, Miwa K, Shinohara A, Iwamatsu A, Nagata S. Identification of a factor that links apoptotic cells to phagocytes. Nature 2002; 417 182-187.

109. Hanayama R, Tanaka M, Miyasaka K, Aozasa K, Koike M, Uchiyama Y et al. Autoimmune disease and impaired uptake of apoptotic cells in MFG-E8-deficient mice. Science 2004 304: $1147-1150$

110. Toda S, Hanayama R, Nagata S. Two-step engulfment of apoptotic cells. Mol Cell Biol 2012; 32: 118-125

111. Pang M, He J, Johnson P, Baum LG. CD45-mediated fodrin cleavage during galectin-1 T cell death promotes phagocytic clearance of dying cells. J Immunol 2009; 182 : 7001-7008

112. Watanabe Y, Shiratsuchi A, Shimizu K, Takizawa T, Nakanishi Y. Role of phosphatidylserine exposure and sugar chain desialylation at the surface of influenza virus-infected cells in efficient phagocytosis by macrophages. J Biol Chem 2002; 277: 18222-18228

113. Meesmann HM, Fehr EM, Kierschke S, Herrmann M, Bilyy R, Heyder P et al. Decrease of sialic acid residues as an eat-me signal on the surface of apoptotic lymphocytes. J Cell Sc 2010; 123: 3347-3356.

114. Rapoport E, Khaidukov S, Baidina O, Bojenko V, Moiseeva E, Pasynina G et al. Involvement of the Galbeta1-3GalNAcbeta structure in the recognition of apoptotic bodies by THP-1 cells. Eur J Cell Biol 2003; 82: 295-302.

115. Eda S, Yamanaka M, Beppu M. Carbohydrate-mediated phagocytic recognition of early apoptotic cells undergoing transient capping of CD43 glycoprotein. J Biol Chem 2004; 279: 5967-5974

116. Ise $H$, Goto M, Komura K, Akaike T. Engulfment and clearance of apoptotic cells based on a GlcNAc-binding lectin-like property of surface vimentin. Glycobiology 2012 22: 788-805.

117. Rapoport EM, Sapot'ko YB, Pazynina GV, Bojenko VK, Bovin NV. Sialoside-binding macrophage lectins in phagocytosis of apoptotic bodies. Biochemistry (Mosc) 2005; 70 330-338.

118. Weck MM, Appel S, Werth D, Sinzger C, Bringmann A, Grünebach F et al. hDectin-1 is involved in uptake and cross-presentation of cellular antigens. Blood 2008; 111 4264-4272.

119. Carlin AF, Chang YC, Areschoug T, Lindahl G, Hurtado-Ziola N, King CC et al. Group B Streptococcus suppression of phagocyte functions by protein-mediated engagement of human Siglec-5. J Exp Med 2009; 206: 1691-1699.

120. Wang $Y$, Neumann $H$. Alleviation of neurotoxicity by microglial human Siglec-11. J Neurosci 2010: 30: 3482-3488.

121. Paessens LC, Fluitsma DM, van Kooyk Y. Haematopoietic antigen-presenting cells in the human thymic cortex: evidence for a role in selection and removal of apoptotic thymocytes. J Pathol 2008; 214: 96-103.

122. Majai G, Gogolák P, Ambrus C, Vereb G, Hodrea J, Fésüs L et al. PPAR $\gamma$ modulated inflammatory response of human dendritic cell subsets to engulfed apoptotic neutrophils. J Leukoc Biol 2010; 88: 981-991. 